\title{
ANALISIS PENYAKIT KARDIOVASKULAR MENGGUNAKAN METODE KORELASI PEARSON, SPEARMAN DAN KENDALL
}

\author{
Yudi Eko Windarto \\ Departemen Teknik Komputer Fakultas Teknik Universitas Diponegoro \\ Jl. Prof Sudharto, SH - Tembalang Semarang \\ Email: yudi@live.undip.ac.id
}

\begin{abstract}
Cardiovascular disease is a disease that is affected by the heart and blood vessels. There are several main risk factors that cause cardiovascular disease. Risk factors for cardiovascular disease include high blood pressure, high cholesterol, diabetes, being overweight or obese, age, sex, smoking, and alcohol. The more risk factors you have, the greater the chance of causing cardiovascular disease. In this research, it was developed using the Spearman, Pearson and Kendall correlation methods to analyze data on cardiovascular disease patients. The results showed there was correlation between blood pressure (ap_hi and ap_lo), age, and cholesterol had a strong relationship with cardiovascular disease. Glucose and cholesterol levels also have a strong relationship between one another.
\end{abstract}

Keyword : Cardiovascular Disease, Factor, Research and Correlation

\section{PENDAHULUAN}

Penyakit kardiovaskular merupakan salah satu penyakit yang dipengaruhi oleh jantung dan pembuluh darah (D’Agostino et al., 2013). Terdapat beberapa faktor risiko utama yang menyebabkan penyakit kardiovaskular (Muggli et al., 2017). Faktor resiko penyakit kardiovaskular antara lain : tekanan darah tinggi, kolesterol tinggi, diabetes, kelebihan berat badan atau obesitas, usia, jenis kelamin, merokok, dan alkohol (Chen et al., 2017). Semakin banyak faktor risiko penyakit yang dimiliki pasien, semakin besar peluang untuk menyebabkan penyakit kardiovaskular (Hajar, 2016).
Penelitian terdahulu yang pernah dilakukan salah satunya membahas tentang diagnosis penyakit jantung coroner. Diagnosis penyakit jantung coroner tersebut menggunakan metode Deep Neural Networks menghasilkan nilai akurasi sebesar $83.67 \%$ (Miao \& Miao, 2018).

Penelitian selanjutnya dengan menggunakan metode machine learning untuk memprediksi penyakit jantung (Jaymin \& Tejal, 2016). Sistem yang dibuat tersebut menggunakan perangkat lunak WEKA.

Penelitian tentang prediksi penyakit jantung menggunakan multiple linear regression model (Polaraju et al., 
2017). Hasil pada penelitian tersebut bergantung pada jumlah atribut yang ada pada data dan metode yang digunakan.

Pada penelitian ini dikembangkan menggunakan metode Korelasi Spearman, Pearson dan Kendall untuk menganalisis data pasien penyakit kardiovaskular.

\section{METODE}

\section{Korelasi}

Analisis korelasi merupakan metode statistika yang digunakan dalam menentukan suatu besaran yang menyatakan adanya hubungan kuat pada suatu variabel dengan variabel yang lain (Uma \& Roger, 2016). Apabila semakin tinggi nilai korelasi, semakin tinggi pula keeratan hubungan diantara kedua variabel. Apabila terdapat angka korelasi mendekati nilai satu, maka korelasi dari dua variabel akan semakin Kuat. Sebaliknya, jika angka korelasi mendekati nol maka korelasi dua variabel semakin lemah (Morris, 2020).

\section{Korelasi Pearson}

Korelasi Pearson adalah salah satu dari pengujian korelasi yang digunakan dalam mengetahui derajat keeratan hubungan dua variabel yang memiliki interval atau rasio, berdistribusi normal, serta mengembalikan nilai koefisien korelasi dengan rentang nilai antara $-1,0$ dan 1 (Zhang et al., 2020). Nilai positif adalah nilai 1 , nilai -1 merupakan nilai negatif, dan nilai 0 merupakan nilai yang tidak terdapat korelasi (Fu et al., 2020).

Rumus dalam menentukan Korelasi Pearson ditunjukkan sebagai berikut.

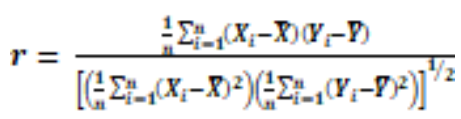

\section{Korelasi Spearman}

Korelasi Spearman dipakai untuk pengukuran korelasi pada statistik nonparametric atau skala ordinal (Bin, Ruodu, dan Yuming, 2019). Korelasi tersebut merupakan ukuran korelasi yang dihubungkan oleh kedua variabel diukur sekurang kurangnya dalam skala ordinal sehingga obyek - obyek penelitiannya dapat diranking dalam dua rangkaian berurut (Andréas, dan Alfonso, 2020). Formula untuk korelasi Spearman ditunjukkan pada persamaan 2 .

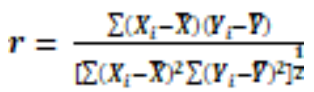

\section{Korelasi Kendall Tau}

Jika terdapat data $\left(\boldsymbol{X}_{\tilde{i}}, \boldsymbol{Y}_{\tilde{i}}\right), i=1,2, \ldots, \mathrm{n}$ di mana $\mathrm{X}$ dan $\mathrm{Y}$ setidaknya berskala ordinal. Sehingga pada setiap pasangan nilai $\left(\boldsymbol{X}_{i}, \boldsymbol{Y}_{i}\right)$ dan $\left(\boldsymbol{X}_{j}, \boldsymbol{Y}_{j}\right)$ untuk $i \neq j$ 
dapat didefinisikan pasangan nilai adalah sebagai berikut (Nugroho et al., 2008):

i). Pasangan $\left(\boldsymbol{X}_{i}, \boldsymbol{Y}_{i}\right)$ dan $\left(\boldsymbol{X}_{j}, \boldsymbol{Y}_{j}\right)$ konkordan jika $\left(\boldsymbol{X}_{\bar{i}}-\boldsymbol{X}_{\boldsymbol{f}}\right)\left(\boldsymbol{Y}_{\dot{i}}-\boldsymbol{Y}_{\boldsymbol{j}}\right)>\mathbf{0}$ artinya adalah jika $\boldsymbol{X}_{\boldsymbol{i}}>\boldsymbol{X}_{\boldsymbol{j}}$ maka $\boldsymbol{Y}_{\boldsymbol{i}}>\boldsymbol{Y}_{\boldsymbol{j}}$ atau jika $\boldsymbol{X}_{i}<\boldsymbol{X}_{j} \quad$ maka $\quad \boldsymbol{Y}_{i}<\boldsymbol{Y}_{j}$ sehingga $\quad(X-\bar{X}) \quad$ dan $\quad(\boldsymbol{Y}-\overline{\boldsymbol{Y}})$ memiliki tanda yang sama, yaitu sama-sama positif atau sama-sama negatif dengan hasil kali yang selalu positif

ii). Pasangan $\left(\boldsymbol{X}_{i}, \boldsymbol{Y}_{i}\right)$ dan $\left(\boldsymbol{X}_{j}, \boldsymbol{Y}_{j}\right)$ diskordan $\quad, \quad$ jika $\left(\boldsymbol{X}_{\boldsymbol{i}}-\boldsymbol{X}_{\boldsymbol{f}}\right)\left(\boldsymbol{Y}_{\boldsymbol{i}}-\boldsymbol{Y}_{j}\right)<0$ artinya adalah jika $\boldsymbol{X}_{\boldsymbol{i}}>\boldsymbol{X}_{\boldsymbol{j}}$ maka $\boldsymbol{Y}_{\boldsymbol{i}}<\boldsymbol{Y}_{\boldsymbol{j}}$ atau jika $\boldsymbol{X}_{\boldsymbol{i}}<\boldsymbol{X}_{\boldsymbol{j}}$ maka $\boldsymbol{Y}_{\boldsymbol{i}}>\boldsymbol{Y}_{\boldsymbol{j}}$ sehingga $(\boldsymbol{X}-\overline{\boldsymbol{X}}) \quad$ dan $\quad(\boldsymbol{Y}-\overline{\boldsymbol{Y}})$ memiliki memiliki tanda yang berlawanan dengan hasil kali yang negative.

Rumus Korelasi Kendall dapat dihitung seperti persamaan 3 (Alexis \& Dean, 2019).

$\tau=\frac{2(C-D)}{n(n-1)}$

\section{HASIL DAN PEMBAHASAN}

Hasil dan Pembahasan penelitian ini terdapat pada beberapa tahapan, diantaranya adalah sebagai berikut:

1. Memasukkan data pasien

2. Membaca data pasien

3. Melakukan analisa data

a) Melakukan uji korelasi data menggunakan metode Spearman

b) Melakukan uji korelasi data menggunakan metode Pearson

c) Melakukan uji korelasi data menggunakan metode Kendall

d) Tahapan penelitian ini ditunjukkan pada gambar 1 .

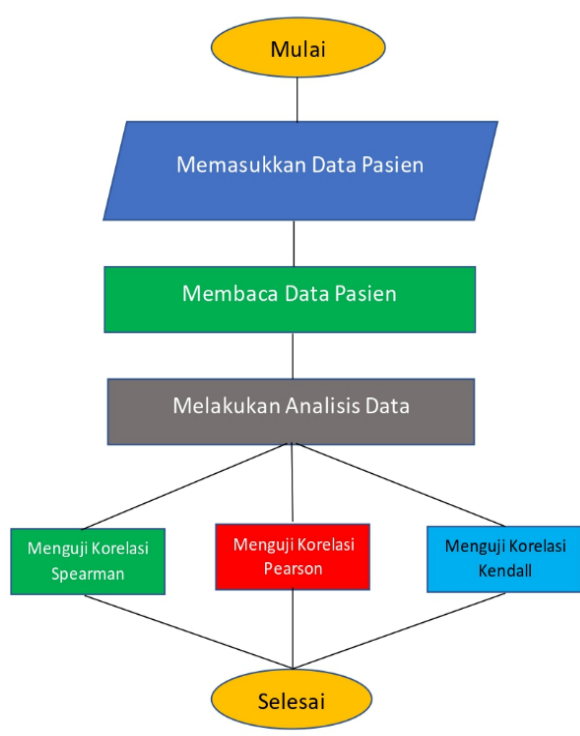

Gambar 1 Tahapan Penelitian

4. Memasukkan data pasien

Tahapan pertama yaitu mengunduh data cardiovascular berdasarkan data yang diperoleh dari dataset kaggle : 
https://www.kaggle.com/datasets.

Selanjutnya memasukkan data pasien menggunakan aplikasi Jupyter Nootebook.

5. Membaca Data Pasien

Tahapan yang kedua adalah membaca data pasien yang ada pada cardiovascular.csv. Data pasien cardiovascular ditunjukkan pada gambar 2.

\begin{tabular}{|c|c|c|c|c|c|c|c|c|c|c|c|c|c|}
\hline 10 & age & gender & height & weight & ap_hi & ap_lo & cholesterol & gluc & $\operatorname{smok}$ & & 100 & active & cardio \\
\hline & 18393 & & 168 & 62.0 & 110 & 80 & 1 & 1 & & 0 & 0 & 1 & \\
\hline & 202288 & 1 & 156 & 85.0 & 140 & 90 & 3 & 1 & & 0 & 0 & & 1 \\
\hline & 18857 & 1 & 165 & 64.0 & 130 & 70 & 3 & 1 & & 0 & 0 & 0 & \\
\hline & 17623 & 2 & 169 & 82.0 & 150 & 100 & 1 & 1 & & 0 & 0 & & \\
\hline & 17474 & 1 & 156 & 56.0 & 100 & 60 & 1 & 1 & & 0 & 1 & n & \\
\hline & 21914 & 1 & 151 & 67.0 & 120 & 80 & 2 & 2 & & 0 & 0 & 0 & 0 \\
\hline & 22113 & 1 & 157 & 93.0 & 130 & 80 & 3 & 1 & & 0 & Q & & 0 \\
\hline 12 & 22584 & 2 & 178 & 95.0 & 130 & 90 & 3 & 3 & & 0 & 0 & 1 & \\
\hline 13 & 17668 & 1 & 158 & 71.0 & 110 & 70 & 1 & 1 & & 0 & 0 & & \\
\hline 14 & 19834 & 1 & 164 & 68.0 & 110 & 60 & 1 & 1 & & 0 & o & & 0 \\
\hline & 22530 & 1 & 169 & 80.0 & 120 & 80 & 1 & 1 & & 0 & 0 & 1 & \\
\hline 16 & 18815 & 2 & 173 & 60.0 & 120 & 80 & 1 & 1 & & & & & \\
\hline 18 & 14791 & 2 & 165 & 60.0 & 120 & 80 & 1 & 1 & & 0 & 0 & & 0 \\
\hline 21 & 19809 & 1 & 158 & 78.0 & 110 & 70 & 1 & 1 & & 0 & 0 & & \\
\hline 23 & 14532 & 2 & 181 & 95.0 & 130 & 90 & 1 & 1 & & 1 & 1 & & \\
\hline 24 & 16782 & 2 & 172 & 112.0 & 120 & 80 & 1 & 1 & & 0 & 0 & & \\
\hline 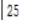 & 212966 & 1 & 170 & 75.0 & 130 & 70 & 1 & 1 & & 0 & 0 & 0 & \\
\hline
\end{tabular}

Gambar 2 Data Pasien

6. Informasi Data

Pada data tersebut terdapat informasi 70.000 data pasien dan 13 kolom yang terdiri dari id, age, gender, height, weight, ap_hi, ap_lo, cholesterol, gluc, smoke, alco, active, cardio ditunjukkan pada gambar 3.

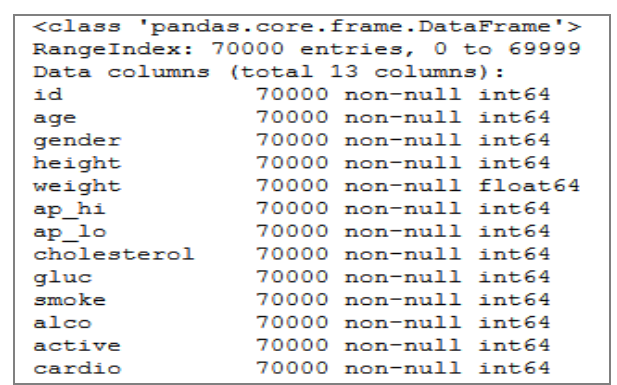

Gambar 3 Informasi Data Pasien
7. Melakukan Analisa Data

Pada tahapan ini, melakukan perbandingan jumlah pasien normal dengan pasien yang memiliki penyakit kardiovaskular. Dari 70.000 terdapat 35.021 jumlah pasien normal dan 34.979 data penderita kardiovaskular. Gambar 4 menunjukkan perbandingan antara pasien normal dengan pasien penderita penyakit kardiovaskular.

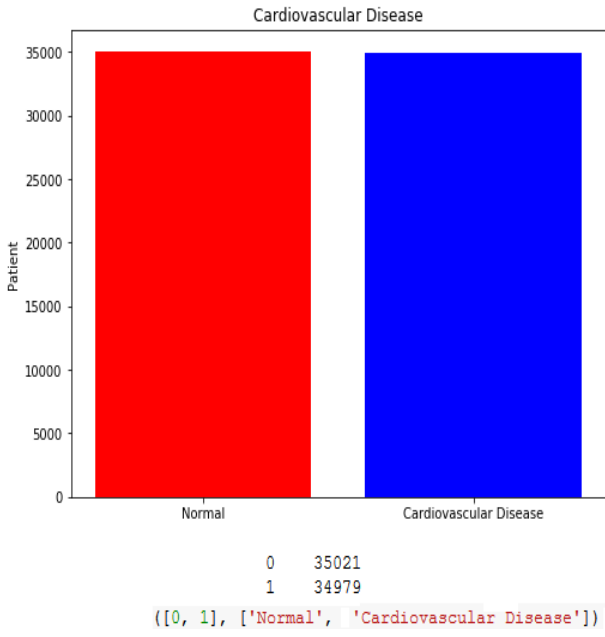

Gambar 4 Perbandingan Pasien Normal dengan Pasien Penderita Kardiovaskular

8. Mendeteksi Pencilan

Pada kolom age, height, weight, ap_hi, ap_lo ada kemungkinan memiliki pencilan. Sehingga untuk membandingkannya pada skala yang sama, perlu melakukan normalisasi data terlebih dahulu. 
Setelah itu perlu meleburkan data untuk menampilkan Multibox Graph Plot seperti gambar 5.

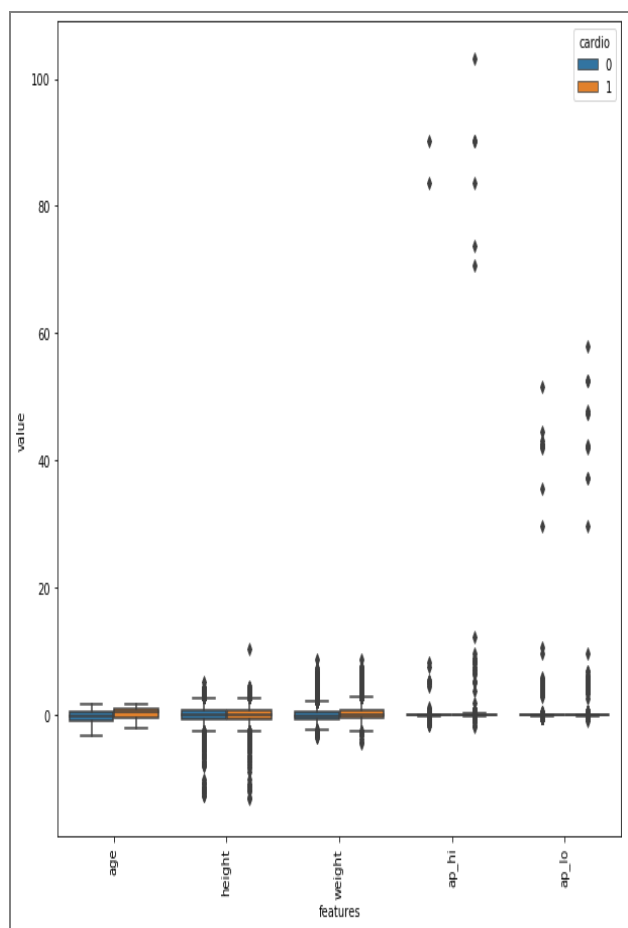

Gambar 5 Multibox Graph Plot

Berdasarkan gambar 5 diatas terdapat beberapa pencilan dalam dataset. Sehingga peneliti harus menentukan batas bawah dan batas atas yang ditunjukkan pada gambar 6.

\begin{tabular}{|crr|}
\hline & ap_hi & ap_lo \\
\hline lower_bound & 90.0 & 65.0 \\
upper_bound & 170.0 & 105.0 \\
\hline
\end{tabular}

Gambar 6 Batas Bawah dan Batas Atas
Penyakit kardiovaskular terdapat 993 data pencilan dari $a p \_h i$ dan $a p \_l o$ di tunjukkan pada gambar 7 .

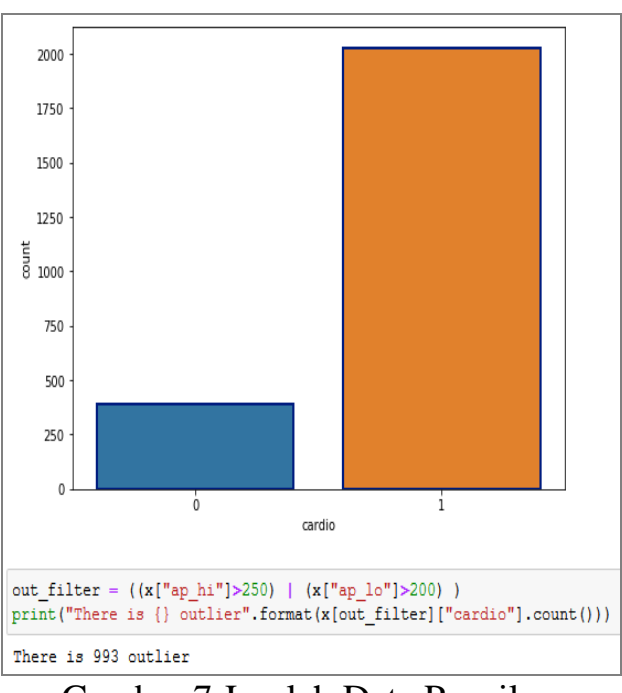

Gambar 7 Jumlah Data Pencilan

Karena $a p \_h i$ dan $a p \_l o$ merupakan tekanan darah, sehingga peneliti memutuskan untuk menghilangkan data yang tidak wajar secara medis dari dataset. Peneliti mengurangi beberapa data untuk mendapat nilai baru yang lebih ideal.

Gambar 8 menunjukkan bahwa terdapat korelasi antara kolesterol, tekanan darah (ap_hi dan ap_low) dan usia memiliki hubungan yang kuat dengan penyakit kardiovaskular.

Kadar gula darah dan kolesterol juga memiliki hubungan yang kuat di antara satu dengan yang lain dengan nilai 0,451 . 


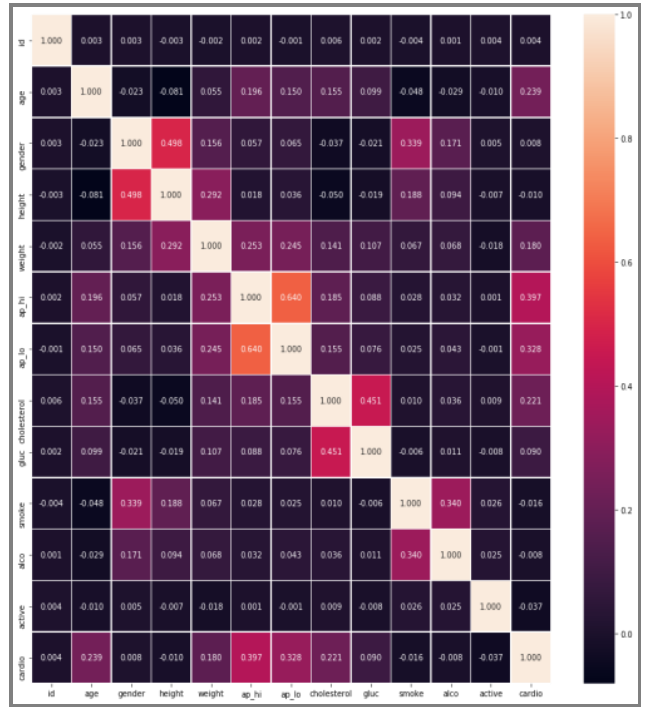

Gambar 8 Korelasi Data

Berdasarkan pada gambar 8 tersebut ternyata yang berkorelasi dengan penyakit kardiovaskular adalah:

1. Tekanan darah sistole (ap_hi) dengan nilai $=0.397$

2. Tekanan darah diastole (ap_lo) dengan nilai $=0.328$

3. Usia dengan nilai $=0.239$

4. Kolesterol dengan nilai $=0,221$

5. Berat badan $=0.180$

6. Kadar gula darah $=0.090$

9. Korelasi Pearson

Pada pengujian menggunakan metode Pearson dihasilkan nilai korelasi dengan penyakit kardiovaskular adalah tekanan darah sistole (ap_hi) dengan nilai $=0.397$, tekanan darah diastole (ap_lo) dengan nilai $=0.328$, usia dengan nilai $=0.239$, kolesterol dengan nilai $=0,221$, berat badan dengan nilai $=$
0.180 dan kadar gula darah dengan nilai $=0.090$.

Hasil pengujian korelasi menggunakan metode Pearson ditunjukkan pada gambar 9 .

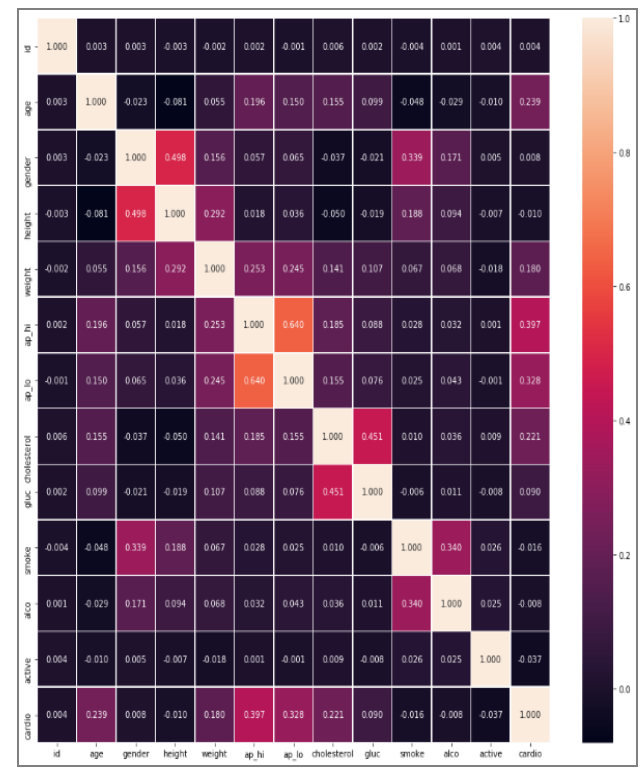

Gambar 9 Korelasi Pearson

10. Korelasi Spearman

Berdasarkan pengujian menggunakan metode Spearman dihasilkan nilai korelasi dengan penyakit kardiovaskular adalah tekanan darah sistole (ap_hi) dengan nilai $=0.447$, tekanan darah diastole (ap_lo) dengan nilai $=0.356$, usia dengan nilai $=0.237$, kolesterol dengan nilai $=0,215$, berat badan dengan nilai $=0.181$ dan kadar gula darah dengan nilai $=0.092$.

Hasil pengujian korelasi menggunakan metode Spearman ditunjukkan pada gambar 10. 


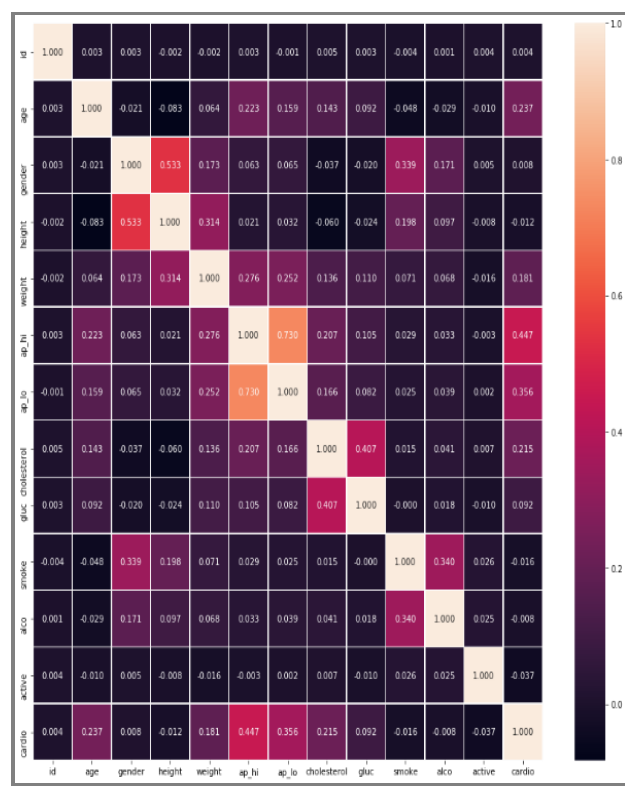

Gambar 10 Korelasi Spearman

11. Korelasi Kendall

Setelah dilakukan pengujian menggunakan metode kendall dihasilkan nilai korelasi dengan penyakit kardiovaskular yaitu tekanan darah sistole (ap_hi) dengan nilai $=0.398$, tekanan darah diastole (ap_lo) dengan nilai $=0.328$, kolesterol dengan nilai $=0.209$, usia dengan nilai $=0.199$, berat badan dengan nilai $=0.149$ dan kadar gula darah dengan nilai $=0.090$.
Hasil pengujian korelasi menggunakan metode Kendall ditunjukkan pada gambar 11 .

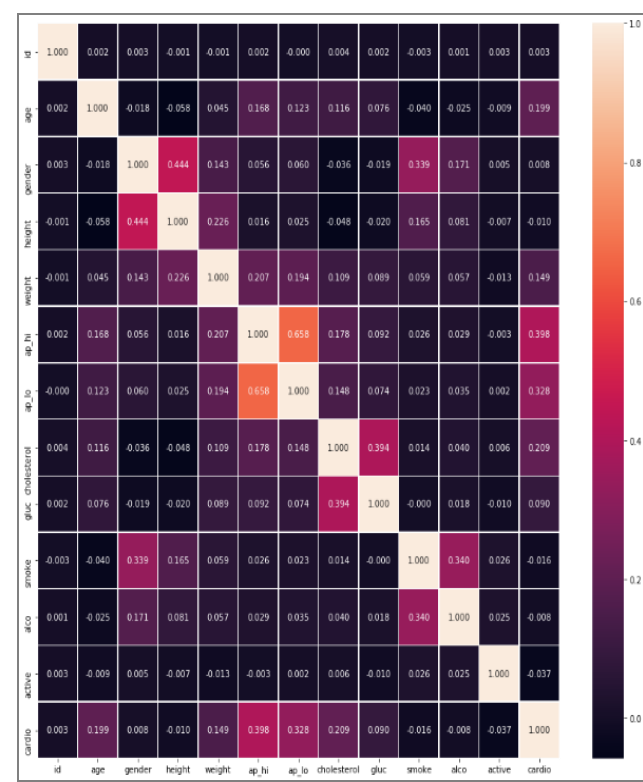

Gambar 11 Korelasi Kendall

Hasil pengujian menggunakan metode Kendall memiliki perbedaan pada urutan korelasi di bandingan pada metode korelasi Pearson dan Spearman. Pada uji korelasi Pearson dan Spearman memiliki urutan sebagai berikut: tekanan darah sistole (ap_hi), tekanan darah diastole (ap_lo), usia, kolesterol, berat badan, dan kadar gula darah. Sebaliknya pada uji korelasi menggunakan metode kendall memiliki urutan sebagai berikut: tekanan darah sistole (ap_hi), tekanan darah diastole (ap_lo), kolesterol, usia, berat badan, dan kadar gula darah. 


\section{DAFTAR PUSTAKA}

Alexis, D., \& Jean, D, F. (2019). A classification point-of-view about conditional Kendall's tau. Computational Statistics \& Data Analysis, 135, 70-94. https://doi.org/10.1016/j.csda.2019. 01.013 .

Andréas, H., \& Alfonso, V. (2020). Spearman rank correlation of the bivariate Student and scale mixtures of normal distributions. Journal of Multivariate Analysis, 179, 1-11. https://doi.org/10.1016/j.jmva.2020. 104650.

Bin, W., Ruodu, W., \& Yuming, W. (2019). Compatible matrices of Spearman's rank correlation. Statistics and Probability Letters, 151, 67-72. https://doi.org/10.1016/j.spl.2019.0 3.015

Chen, W. W., Gao, R. L., Liu, L. S., Zhu, M. L., Wang, W., Wang, Y. J., $\mathrm{Hu}$, S. S. (2017). China cardiovascular diseases report 2015: A summary. Journal of Geriatric Cardiology, 14(1), 1-10. https://doi.org/10.11909/j.issn.1671 -5411.2017 .01 .012 .

D’Agostino, R. B., Pencina, M. J., Massaro, J. M., \& Coady, S. (2013). Cardiovascular disease risk assessment: Insights from Framingham. Global Heart, 8(1), 11-23. https://doi.org/10.1016/j.gheart.201 3.01.001.

Fu, T., Tang, X., Cai, Z., Zuo, Y., Tang, Y., \& Zhao, X. (2020). Correlation research of phase angle variation and coating performance by means of Pearson's correlation coefficient.
Progress in Organic Coatings, 139(October 2019), 105459. https://doi.org/10.1016/j.porgcoat.2 019.105459 .

Hajar, R. (2016). Framingham contribution to cardiovascular disease. Heart Views, 17(2), 78. https://doi.org/10.4103/1995$705 x .185130$.

Jaymin, P., Tejal, U., S. (2016). Heart Disease Prediction Using Machine learning and Data Mining Technique. 7, 129-137. https://doi.org/10.090592/IJCSC.20 16.018 .

Miao, K. H., \& Miao, J. H. (2018). Coronary heart disease diagnosis using deep neural networks. International Journal of Advanced Computer Science and Applications, 9(10), 1-8. https://doi.org/10.14569/IJACSA.2 018.091001 .

Morris, A. (2020). A more scientific approach to applied economics: Reconstructing statistical, analytical significance, and correlation analysis. Economic Analysis and Policy, 66, 315-324.

Muggli, F., Rabufetti, A., Simonetti, Gd., Bianchetti, Mg., Gallino, A. (2017). CARDIOVASCULAR DISEASE RISK FACTORS AMONG MALE YOUTHS IN SOUTHERN SWITZERLAND: A TRANSVERSAL STUDY. 2017.

Polaraju, K., Durga Prasad, D., \& Tech Scholar, M. (2017). Prediction of Heart Disease using Multiple Linear Regression Model. International Journal of Engineering Development and Research, 5(4), 2321-9939. 
Uma, S., \& Roger, B. (2016). Research Methods For Business: A Skill Building Approach. In Encyclopedia of Quality of Life and Well-Being Research (7th ed.). https://doi.org/10.1007/978-94-0070753-5_102084.

Zhang, Y., Li, Y., Song, J., Chen, X., Lu, Y., \& Wang, W. (2020). Pearson correlation coefficient of current derivatives based pilot protection scheme for long-distance LCCHVDC transmission lines. International Journal of Electrical Power and Energy Systems, 116(September 2019), 105526. https://doi.org/10.1016/j.ijepes.201 9.105526 . 